\title{
High intake of heterocyclic amines from meat is associated with oxidative stress
}

\author{
A. M. Carvalho ${ }^{1}$, A. M. Miranda ${ }^{1}$, F. A. Santos ${ }^{2}$, A. P. M. Loureiro ${ }^{2}$, R. M. Fisberg ${ }^{1}$ and D. M. Marchioni ${ }^{1 *}$ \\ ${ }^{1}$ Department of Nutrition, School of Public Health, University of Sao Paulo, SP, Brazil \\ ${ }^{2}$ Department of Clinical and Toxicological Analysis, Faculty of Pharmaceutical Sciences, University of Sao Paulo, \\ Sao Paulo, SP, Brazil \\ (Submitted 1 July 2014 - Final revision received 16 January 2015 - Accepted 5 February 2015 - First published online 27 March 2015)
}

\section{Abstract}

High meat intake has been related to chronic diseases such as cancer and CVD. One hypothesis is that heterocyclic amines (HCA), which are formed during the cooking process of meat, can generate reactive species. These compounds can cause oxidation of lipids, proteins and DNA, resulting in oxidative stress, cell damage and loss of biological function. This association has been seen in vitro; however, it remains unclear in vivo. The aim of the present study was to investigate the association between oxidative stress and HCA intake, and oxidative stress and meat intake. Data were from the Health Survey for Sao Paulo - ISA-Capital (561 adult and elderly). Food intake was estimated by one 24-h dietary recall (24HR) complemented by a detailed FFQ with preferences of cooking methods and level of doneness for meat. HCA intake was estimated linking the meat from the $24 \mathrm{HR}$ to a database of HCA. Oxidative stress was estimated by malondialdehyde (MDA) concentration in the plasma, after derivatisation with thiobarbituric acid and quantification by HPLC/diode array. Analyses were performed using multivariate logistic regressions adjusted for smoking, sex, age, BMI, skin colour, energy intake, fruit and vegetable intake, and physical activity. A positive association between HCA intake and MDA concentration (OR 1.17; $95 \%$ CI $1.01,1.38$ ) was observed, showing that HCA from meat may contribute to increase oxidative stress, and may consequently increase the risk of chronic diseases.

Key words: Meat: Heterocyclic amines: Oxidative stress

Meat is an important food item for human nutrition ${ }^{(1)}$; however, excessive meat intake, especially red and processed meat, has been linked to chronic diseases ${ }^{(2)}$ such as $\mathrm{CVD}^{(3)}$ and cancer ${ }^{(4)}$. According to a recent systematic review and a meta-analysis, involving more than one million people, the intake of $50 \mathrm{~g} / \mathrm{d}$ of processed meat increases the risk of CVD by $42 \%$, and of diabetes by $19 \%{ }^{(3)}$. Another meta-analysis $^{(5)}$ has reported that the intake of $110 \mathrm{~g} / \mathrm{d}$ of red meat is associated with a $27 \%$ increased risk of colorectal cancer, and the intake of $50 \mathrm{~g} / \mathrm{d}$ of processed meat is associated with a $29 \%$ increased risk of colorectal cancer. Other studies have reported an association between red and processed meat intake and risk of cancer of the stomach ${ }^{(6)}$, oesophagus $^{(7,8)}$, lungs ${ }^{(9)}$ and other organs.

There are some reasons for meat to be linked to the risk of chronic diseases, such as heterocyclic amines (HCA) that are potentially carcinogenic substances, formed during the cooking process of meat (baking, frying and barbequing) ${ }^{(3,10)}$, besides high saturated fat content, high cholesterol content, $\mathrm{Na}$ and nitrites that are added to processed meat.

During HCA metabolism, reactive species are formed, especially by cytochrome $\mathrm{P} 450$, which can cause oxidation of lipids, proteins and nucleic acids, resulting in oxidative stress, cell damage and loss of biological function, thus increasing the risk of CVD and cancer ${ }^{(4,11-13)}$.

The levels of HCA formed are highly dependent on the type of meat cooked, the method, the temperature and the duration of cooking ${ }^{(14,15)}$, ranging from 1 to $80 \mathrm{ng} / \mathrm{g}$ of meat for PhIP (2-amino-1-methyl-6-phenylimidazo[4,5-b]pyridine), the most abundant HCA in the human diet, followed by MeIQx (2-amino-3,8-dimethylimidazo[4,5-f]quinoxaline) with usual amounts up to $6 \mathrm{ng} / \mathrm{g}$ of meat and DiMeIQx (2-amino3,4,8-dimethylimidazo[4,5-f]quinoxaline) with amounts up to $1 \mathrm{ng} / \mathrm{g}$ of meat ${ }^{(16)}$.

Despite the proven genotoxicity in various organisms, such as bacteria, Drosophila, cells in vitro and experimental rodents in vivo, the data are inconsistent in humans because it is

Abbreviations: 24HR, 24-h dietary recall; DiMeIQx, 2-amino-3,4,8-dimethylimidazo[4,5- $f$ ]quinoxaline; HCA, heterocyclic amines; MDA, malondialdehyde; MeIQx, 2-amino-3,8-dimethylimidazo[4,5-f]quinoxaline; PhIP, 2-amino-1-methyl-6-phenylimidazo[4,5- $b$ ]pyridine.

*Corresponding author: D. M. Marchioni, fax +55 113061 7804, email marchioni@usp.br 
difficult to identify the specific cell damage caused by HCA metabolism, and to estimate HCA intake $\mathrm{e}^{(10,17-19)}$.

The aim of the present study was to investigate the association between HCA intake and oxidative stress, and the association between meat intake and oxidative stress.

\section{Experimental methods}

\section{Study population and data collection}

Data were obtained from a representative, complex, multistage probability-based cross-sectional study titled the Health Survey for Sao Paulo (ISA-Capital) conducted in Sao Paulo, Brazil, in 2008 and 2009. This survey collected information on health, food intake and lifestyle factors of the population of Sao Paulo city, an important financial and commercial centre in Latin America, and the most populous city in Brazil with approximately eleven million inhabitants in 2008 .

A two-stage cluster sampling was used: census tracts and household. In the first stage, the census tracts were drawn using the probability of the number of households. In the second stage, the households were drawn using an inverse probability of the number of households. The drawing was systematic, and six study domains were defined by age groups and sex: females and males aged 13-19 years old (adolescents), 20-59 years old (adults) and 60 years old or over (elderly). It was estimated that a minimum sample size of 300 in each of the six domains was needed based on a prevalence of 0.5 with a standard error of 0.07 at a $5 \%$ significance level and a design effect of 1.5. A total of 2691 individuals were selected to answer questions about life conditions and sociodemographic information.

After 1 year, a new contact was attempted with the same number of participants ( $n$ 2691) to new data collection (dietetic, biochemical, anthropometrical and sociodemographic information). After three tentative visits, made at different times (during weekdays and weekends), and six tentative telephone contacts, $62 \%$ of the initial sample (1662 individuals) agreed to participate. Of those, 750 subjects (adolescents, adults and elderly) donated a blood sample. For the present study, only adults and elderly ( $n$ 561) were included.

Although the proportion of individuals who completed the study was similar by census tract and sociodemographic characteristics compared with the original sample, sampling weights were recalculated for each individual considering the sample design, non-response and post-stratification adjustment for sex and age group, in order to equalise the sociodemographic features of the sample. The School of Public Health of the University of São Paulo Ethics Committee approved the project. An informed consent form was obtained from all the participants.

\section{Assessment of dietary intake}

For the present study, dietary intake was estimated by one 24-h dietary recall (24HR). It was collected over 1 year covering all weekdays, weekends and seasons ${ }^{(20)}$, administered by telephone using the Automated Multiple-Pass Method $^{(21)}$. The telephone calls were made to the participant's home or their mobile phone. This method is structured in five steps: (1) quick list, where participants list all the foods and beverages consumed uninterruptedly; (2) forgotten list, where participants are asked about commonly forgotten foods consumed, such as candies, coffees and sodas; (3) time and location of food and beverage intake; (4) detailing cycle, where the way of preparation and amounts consumed are described; (5) final review, that verifies whether a certain food consumed during the day was not previously recorded ${ }^{(21,22)}$.

The household measures reported in 24HR were converted into $\mathrm{g}$ and $\mathrm{ml}$ according to standard Brazilian references, which measured many foods using a precision balance ${ }^{(23,24)}$. Recipes were broken down into ingredients in order to estimate the amount of meat in each preparation.

Data from the $24 \mathrm{HR}$ were entered into the Nutrition Data System for Research - NDSR (version 5.0, 2007, Nutrition Coordinating Center at the University of Minnesota, Minneapolis, MN, USA) ${ }^{(25)}$, and were converted into energy and nutrients. The American database for the nutrition facts (energy, protein, carbohydrate and lipid) from the NDSR and the Brazilian nutrition facts database were compared. Only the foods from the NDSR that were similar (between 0.8 until 1.2 times) to Brazilian nutrition facts in terms of energy and macronutrients were considered.

Additionally, a detailed FFQ, based on the FFQ developed and validated by Cantwell et $a l .{ }^{(26)}$, was administered to each participant, containing information regarding the frequency of consumption of each food item, meat cooking preference (pan-fried, grilled, boiled, baked and microwaved) and level of meat doneness preference (medium, well done, and very well done for poultry and pork, and rare, medium, well done, and very well done for beef).

The amount of meat intake was estimated by the $24 \mathrm{HR}$. The preferences of cooking methods and degrees of cooking, collected in the FFQ, were inputted in the $24 \mathrm{HR}$ to estimate the intake of HCA. These data were linked to the Computerized Heterocyclic Amines Resource for Research in Epidemiology of Disease (CHARRED) database to estimate the values of three HCA (PhIP, MeIQx and DiMeIQx).

\section{Biochemical marker}

Blood samples were obtained by venepuncture after a 12-h overnight fast by a nursing assistant. They were kept in a polystyrene box with ice packs, and transported to the laboratory for immediate centrifugation for $15 \mathrm{~min}$ at room temperature. After centrifugation, plasma samples were aliquoted and frozen at $-80^{\circ} \mathrm{C}$ until analysis.

The concentration of malondialdehyde (MDA) in the plasma was determined after derivatisation with thiobarbituric acid and quantification by HPLC/diode array, as

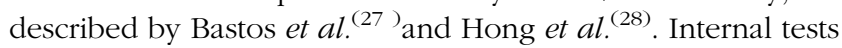
revealed within-assay $\mathrm{CV}$ around $5 \%$, and between-assay CV around $16 \%$. The participants were divided into two groups based on the median of MDA concentration. The variable MDA was normally distributed, as determined by the Kolmogorov-Smirnov test. 


\section{Anthropometric measures}

A trained research nurse measured body weight and height, using a standardised protocol. BMI was calculated as weight (in $\mathrm{kg}$ ) divided by the square of height (in $\mathrm{m}$ ). Nutritional status was determined based on BMI, using the cut-off points proposed by the $\mathrm{WHO}^{(29)}$ for adults and by Lipschitz ${ }^{(30)}$ for the elderly.

\section{Statistical analyses}

Multivariate logistic regression models were estimated to verify the associations between the dependent variable (MDA concentration) and the following independent variables: meat intake (continuous variable); HCA intake (continuous variable); PhIP intake (continuous variable); MeqIQx intake (continuous variable); DiMeqIQx intake (continuous variable). The first model was a crude model (without co-variables); the second model was adjusted for age (continuous variable) and sex (female and male); the third model was further adjusted for energy intake (continuous variable), smoking (yes, no), BMI (healthy, overweight), skin colour (white, non-white), fruit and vegetable intake (continuous variable) and physical activity (active or not). OR and 95\% CI were estimated.

In the stratified analysis, mean and 95\% CI of MDA concentration were estimated according to the cooking methods and doneness levels for each kind of meat studied.

Differences between means were analysed using the Wald test, which calculates point estimates using $F$-statistics and (Mean values with their standard errors) considers the weights from complex samples. For categorical variables, the $\chi^{2}$ test was performed to compare the distribution of demographic characteristics. All analyses were conducted using the appropriate sample weights to account for the complex survey design. For all analyses, STATA ${ }^{\circledR}$ statistical software package version 10 (Stata Corporation) was used, and $P<0.05$ was considered statistically significant.

\section{Results}

The sample comprised 39\% men and 61\% women; $52 \%$ adults and $48 \%$ elderly. The means and standard error of food intake and sociodemographic information are presented in Table 1. Participants were divided into two groups based on the median of MDA concentration.

The median MDA concentration was $0.71 \mu \mathrm{mol} / 1$ (25th percentile $0.49 \mu \mathrm{mol} / 1 ; 75$ th percentile $0.92 \mu \mathrm{mol} / 1)$, and it was not different between sex, smoking, skin colour and physical activity. Participants, who presented a MDA concentration above the median, consumed more HCA and PhIP than the below median participants. The same was not observed with DiMeIQx, MeIQx and meat intake (Table 1).

PhIP was the most consumed HCA, and beef was the most consumed meat (Table 1). 'Well done' was the doneness most cited among all varieties of meat, and pan-fried was the cooking method most mentioned. Beef contributed more to HCA amounts, followed by poultry and then pork (Table 2).

Participants who consumed grilled beef very well done presented more MDA concentration than other participants (Table 3).

Table 1. Descriptive characteristics of participants in the Health Survey for Sao Paulo (ISA-Capital) study

\begin{tabular}{|c|c|c|c|c|c|c|c|}
\hline & \multirow[b]{2}{*}{ Mean } & \multirow[b]{2}{*}{ SE } & \multicolumn{2}{|c|}{$\begin{array}{c}\mathrm{MDA}<0.71 \\
\mu \mathrm{mol} / \mathrm{l}\end{array}$} & \multicolumn{2}{|c|}{$\begin{array}{c}\mathrm{MDA}>0.71 \\
\mu \mathrm{mol} / \mathrm{l}\end{array}$} & \multirow[b]{2}{*}{$P^{\star}$} \\
\hline & & & Mean & SE & Mean & SE & \\
\hline Energy intake (kcal/d) & 1689 & $56 \cdot 8$ & 1625 & $63 \cdot 7$ & 1749 & $99 \cdot 6$ & 0.30 \\
\hline HCA intake (ng/d) & $436 \cdot 8$ & $45 \cdot 6$ & $329 \cdot 8$ & $43 \cdot 4$ & $503 \cdot 8$ & $61 \cdot 3$ & 0.01 \\
\hline Total PhIP (ng/d) & $324 \cdot 3$ & $36 \cdot 2$ & 233.9 & 33.7 & $385 \cdot 3$ & $50 \cdot 3$ & 0.01 \\
\hline Total MelQx (ng/d) & $102 \cdot 7$ & $13 \cdot 0$ & $87 \cdot 6$ & $12 \cdot 9$ & $108 \cdot 1$ & $19 \cdot 1$ & 0.33 \\
\hline Total DiMelQx (ng/d) & $9 \cdot 8$ & 1.5 & $8 \cdot 3$ & 1.6 & $10 \cdot 3$ & $2 \cdot 3$ & 0.45 \\
\hline Energy-adjusted HCA intake (ng/4184 kJ(1000 kcal)) & 258.6 & $26 \cdot 0$ & 209.9 & $27 \cdot 0$ & $287 \cdot 8$ & 34.9 & 0.04 \\
\hline Energy-adjusted PhIP intake (ng/4184 kJ (1000 kcal)) & $194 \cdot 0$ & $21 \cdot 0$ & $146 \cdot 8$ & $19 \cdot 0$ & $226 \cdot 4$ & $30 \cdot 3$ & 0.01 \\
\hline Energy-adjusted MelQx intake (ng/4184 kJ (1000 kcal)) & $59 \cdot 0$ & $6 \cdot 9$ & $57 \cdot 6$ & $9 \cdot 4$ & $56 \cdot 1$ & $8 \cdot 1$ & 0.89 \\
\hline Energy-adjusted DiMelQx intake (ng/4184 kJ (1000 kcal)) & $5 \cdot 6$ & 0.8 & $5 \cdot 7$ & $1 \cdot 1$ & $5 \cdot 6$ & 0.9 & 0.97 \\
\hline Total meat intake $(\mathrm{g} / \mathrm{d})$ & $135 \cdot 1$ & $7 \cdot 1$ & $123 \cdot 7$ & $10 \cdot 2$ & $144 \cdot 0$ & $9 \cdot 8$ & $0 \cdot 16$ \\
\hline Beef intake $(g / d)$ & $64 \cdot 8$ & $6 \cdot 3$ & $66 \cdot 8$ & 8.7 & 62.5 & $7 \cdot 6$ & 0.68 \\
\hline Poultry intake (g/d) & $33 \cdot 2$ & $4 \cdot 0$ & $26 \cdot 2$ & 4.9 & $36 \cdot 9$ & 4.9 & 0.11 \\
\hline Pork intake $(g / d)$ & $23 \cdot 3$ & $4 \cdot 3$ & $18 \cdot 5$ & $2 \cdot 5$ & $28 \cdot 7$ & $7 \cdot 5$ & 0.15 \\
\hline Processed meat intake (g/d) & 23.4 & $3 \cdot 2$ & $24 \cdot 2$ & $3 \cdot 1$ & $22 \cdot 6$ & $5 \cdot 4$ & 0.80 \\
\hline Fruit and vegetable intake $(\mathrm{g} / \mathrm{d})$ & $189 \cdot 2$ & $16 \cdot 1$ & $177 \cdot 1$ & $17 \cdot 2$ & $199 \cdot 1$ & $22 \cdot 4$ & 0.32 \\
\hline Malondialdehyde $(\mu \mathrm{mol} / \mathrm{l})$ & 0.72 & 0.02 & 0.48 & 0.02 & 0.96 & 0.02 & $<0.01$ \\
\hline Age (years) & $46 \cdot 1$ & $1 \cdot 2$ & $44 \cdot 3$ & 1.5 & $47 \cdot 8$ & $1 \cdot 3$ & 0.03 \\
\hline $\mathrm{BMI}$ & $26 \cdot 5$ & 0.3 & $25 \cdot 4$ & 0.4 & $27 \cdot 5$ & 0.4 & $<0.01$ \\
\hline Sex (\% men) & \multicolumn{2}{|c|}{$39 \cdot 1$} & \multicolumn{2}{|c|}{$34 \cdot 0$} & \multicolumn{2}{|c|}{$44 \cdot 1$} & 0.12 \\
\hline Smoking (\%) & \multicolumn{2}{|c|}{$23 \cdot 0$} & \multicolumn{2}{|c|}{22.9} & \multicolumn{2}{|c|}{$23 \cdot 1$} & 0.97 \\
\hline Skin colour (\% white) & \multicolumn{2}{|c|}{$60 \cdot 6$} & \multicolumn{2}{|c|}{$43 \cdot 4$} & \multicolumn{2}{|c|}{$36 \cdot 7$} & 0.25 \\
\hline Physical activity (\% active) & \multicolumn{2}{|c|}{$21 \cdot 6$} & \multicolumn{2}{|c|}{$23 \cdot 4$} & \multicolumn{2}{|c|}{$20 \cdot 4$} & 0.58 \\
\hline
\end{tabular}

MDA, malondialdehyde; HCA, heterocyclic amines; PhIP, 2-amino-1-methyl-6-phenylimidazo[4,5-b]pyridine; MelQx, 2-amino-3,8-dimethylimidazo [4,5-f]quinoxaline; DiMelQx, 2-amino-3,4,8-dimethylimidazo[4,5-f]quinoxaline.

${ }^{*} \chi^{2}$ for categorical variables; Wald-test for continuous variables. 
Table 2. Cooking methods, doneness level preferences and heterocyclic amine (HCA) intake in the Health Survey for Sao Paulo (ISA-Capital) study

\begin{tabular}{|c|c|c|c|c|c|c|}
\hline Doneness level & $\%$ & Cooking methods & $\%$ & $\mathrm{HCA}$ & Mean & SE \\
\hline \multicolumn{7}{|l|}{ Beef } \\
\hline Rare & $5 \cdot 2$ & Boiled & $37 \cdot 8$ & MeQIx & $74 \cdot 3$ & 9.9 \\
\hline Medium & $27 \cdot 4$ & Pan-fried & $41 \cdot 0$ & PhIP & 201.5 & 29.0 \\
\hline Well done & 57.5 & Baked & $6 \cdot 7$ & DiMelQx & $7 \cdot 0$ & 1.3 \\
\hline Very well done & 9.9 & $\begin{array}{l}\text { Grilled } \\
\text { Microwaved }\end{array}$ & $\begin{array}{c}14 \cdot 5 \\
*\end{array}$ & Total HCA & $282 \cdot 9$ & 38.9 \\
\hline \multicolumn{7}{|l|}{ Pork } \\
\hline Medium & $18 \cdot 6$ & Boiled & $17 \cdot 0$ & MeQIx & $22 \cdot 3$ & 8.0 \\
\hline Well done & $65 \cdot 0$ & Pan-fried & 59.9 & PhIP & 0 & \\
\hline \multirow[t]{3}{*}{ Very well done } & $16 \cdot 4$ & Baked & 17.4 & DiMelQx & $2 \cdot 0$ & 0.6 \\
\hline & & Grilled & $5 \cdot 6$ & Total HCA & $24 \cdot 3$ & 8.6 \\
\hline & & Microwaved & 0.1 & & & \\
\hline \multicolumn{7}{|l|}{ Poultry } \\
\hline Medium & $8 \cdot 6$ & Boiled & 29.4 & MeQIx & $6 \cdot 2$ & $1 \cdot 3$ \\
\hline Well done & $60 \cdot 0$ & Pan-fried & $38 \cdot 1$ & PhIP & 122.5 & $17 \cdot 2$ \\
\hline \multirow[t]{3}{*}{ Very well done } & 31.4 & Baked & $17 \cdot 1$ & DiMelQx & 0.8 & 0.1 \\
\hline & & Grilled & $15 \cdot 4$ & Total HCA & $129 \cdot 7$ & $18 \cdot 3$ \\
\hline & & Microwaved & ${ }^{*}$ & & & \\
\hline
\end{tabular}

MelQx, 2-amino-3,8-dimethylimidazo[4,5-f]quinoxaline; PhIP, 2-amino-1-methyl-6-phenylimidazo[4,5- $b$ ]pyridine; DiMelQx, 2-amino-3,4,8-dimethylimidazo[4,5-f]quinoxaline.

${ }^{*}$ No one reported meat intake in the specific cooking method.

Table 4 shows the multivariate-adjusted OR for MDA $>0.71 \mu \mathrm{mol} / 1$ by total meat intake and types of HCA intake. Positive and significant relationships between total HCA intake and MDA, as PhIP intake and MDA $(P<0 \cdot 05)$, were observed. They remained significant after adjustment for smoking, sex, age, BMI, skin colour, energy, fruit and vegetable intake, and physical activity. However, MeIQx, DiMeIQx and meat intake were not significantly associated with MDA concentration.

\section{Discussion}

The present study reported positive relationships between MDA concentration and HCA and PhIP intake in a population-based study. It showed that MDA concentration in the plasma can be increased by an intake of high total HCA and PhIP from meat, even after adjustment for sex, age, skin colour, physical activity, and intake of fruit, vegetable and energy, which can increase the risk of CVD and cancer.

Table 3. Malondialdehyde (MDA) concentration level by cooking methods and doneness levels for each meat intake in the Health Survey for Sao Paulo (ISA-Capital) study

(Mean values and $95 \%$ confidence intervals)

\begin{tabular}{|c|c|c|c|c|c|c|c|}
\hline \multirow[b]{3}{*}{ Doneness levels } & \multirow[b]{3}{*}{ Cooking methods } & \multicolumn{6}{|c|}{ MDA mean $(\mu \mathrm{mol} / \mathrm{l})$} \\
\hline & & \multicolumn{2}{|c|}{ Beef } & \multicolumn{2}{|c|}{ Pork } & \multicolumn{2}{|c|}{ Poultry } \\
\hline & & Mean & $95 \% \mathrm{Cl}$ & Mean & $95 \% \mathrm{Cl}$ & Mean & $95 \% \mathrm{Cl}$ \\
\hline \multirow{5}{*}{ Rare } & Boiled & 0.73 & $0.53,0.92$ & & & & \\
\hline & Baked & 0.66 & $0.47,0.85$ & & & & \\
\hline & Grilled & * & * & & & & \\
\hline & Pan fried & 0.66 & $0.47,0.85$ & & & & \\
\hline & Microwaved & * & & & & & \\
\hline \multirow[t]{5}{*}{ Done } & Boiled & 0.75 & $0.65,0.85$ & 0.67 & $0.52,0.81$ & 0.60 & $0.45,0.74$ \\
\hline & Baked & 0.80 & $0.64,0.97$ & 0.74 & $0.34,1.13$ & 0.58 & $0.27,0.88$ \\
\hline & Grilled & 0.76 & $0.60,0.92$ & * & * & 0.80 & $0.59,1.01$ \\
\hline & Pan fried & 0.67 & $0.58,0.76$ & 0.58 & $0.41,0.74$ & 0.82 & $0.61,0.76$ \\
\hline & Microwaved & * & * & * & * & * & * \\
\hline \multirow[t]{5}{*}{ Well done } & Boiled & 0.73 & $0.66,0.80$ & 0.84 & $0.73,0.94$ & 0.75 & $0.68,0.82$ \\
\hline & Baked & 0.60 & $0.40,0.80$ & 0.72 & $0.63,0.81$ & 0.77 & $0.65,0.89$ \\
\hline & Grilled & 0.83 & $0.67,0.99$ & 0.66 & $0.32,0.99$ & 0.80 & $0.69,0.91$ \\
\hline & Pan-fried & 0.71 & $0.62,0.80$ & 0.68 & $0.62,0.75$ & 0.73 & $0.65,0.92$ \\
\hline & Microwaved & * & * & * & * & * & * \\
\hline \multirow[t]{5}{*}{ Very well done } & Boiled & 0.73 & $0.45,1.00$ & 0.95 & $0.63,1.26$ & 0.71 & $0.56,0.86$ \\
\hline & Baked & 0.66 & $0.43,0.89$ & 0.72 & $0.57,0.86$ & 0.51 & $0.34,0.68$ \\
\hline & Grilled & 1.83 & $1 \cdot 36,2 \cdot 30$ & 0.70 & $0.07,1.32$ & 1.00 & $0.69,1.30$ \\
\hline & Pan-fried & 0.68 & $0.54,0.82$ & 0.66 & $0.57,0.75$ & 0.64 & $0.57,0.70$ \\
\hline & Microwaved & * & * & * & * & * & * \\
\hline
\end{tabular}

*Less than two participants reported meat intake in the specific cooking method and doneness level. 
Table 4. Association between malondialdehyde concentration levels (above and below $0.71 \mu \mathrm{mol} / \mathrm{l}$ ) and kinds of heterocyclic amines (HCA) and meat intake in the Health Survey for Sao Paulo (ISA-Capital) study

(Odds ratios and $95 \%$ confidence intervals)

\begin{tabular}{|c|c|c|c|c|c|c|c|c|c|}
\hline & \multicolumn{3}{|c|}{ Model $1^{*}$} & \multicolumn{3}{|c|}{ Model $2 \dagger$} & \multicolumn{3}{|c|}{ Model 3ł } \\
\hline & OR & $95 \% \mathrm{Cl}$ & $P$ & OR & $95 \% \mathrm{Cl}$ & $P$ & OR & $95 \% \mathrm{Cl}$ & $P$ \\
\hline Meat intake $(100 \mathrm{~g})$ & 1.00 & $0.99,1.00$ & 0.20 & 1.00 & $0.99,1.00$ & 0.25 & 1.00 & $0.99,1.00$ & 0.51 \\
\hline HCA intake (500 ng) & $1 \cdot 18$ & $1.03,1.35$ & 0.02 & $1 \cdot 18$ & $1.02,1.36$ & 0.03 & $1 \cdot 17$ & $1.01,1.38$ & 0.04 \\
\hline PhIP intake (500 ng) & 1.26 & $1.05,1.50$ & 0.01 & 1.26 & $1.04,1.52$ & 0.02 & 1.26 & $1.04,1.53$ & 0.02 \\
\hline MelQx intake (100 ng) & 1.05 & $0.95,1.17$ & 0.31 & 1.05 & $0.94,1.16$ & 0.40 & 1.05 & $0.93,1.17$ & 0.45 \\
\hline DiMelQx intake (1 ng) & 1.00 & $0.99,1.01$ & 0.42 & 1.00 & $0.99,1.01$ & 0.52 & 1.00 & $0.99,1.01$ & 0.55 \\
\hline
\end{tabular}

PhIP, 2-amino-1-methyl-6-phenylimidazo[4,5-b]pyridine; MeIQx, 2-amino-3,8-dimethylimidazo[4,5-f]quinoxaline; DiMeIQx, 2-amino-3,4,8dimethylimidazo[4,5- $f$ ]quinoxaline.

* Model 1: Crude model.

† Model 2: Adjusted for age and sex.

‡ Model 3: Adjusted for age, sex, smoking, BMI, energy intake, fruit and vegetable intake, skin colour and physical activity.

Many studies ${ }^{(31-33)}$ have shown that HCA, especially PhIP, can produce reactive species and induce lipid peroxidation in vitro. A recent study has shown the relationship between PhIP intake and increased oxidative stress assessed by lipid peroxidation and protein oxidation in rats ${ }^{(34)}$. Other studies have reported that oxidative stress increases the risk of chronic diseases $^{(35,36)}$

A hypothesis to explain that relationship between HCA and MDA is the biotransformation of HCA, which is a complex process to facilitate the excretion of these molecules. However, during the metabolism, unstable products (reactive species) can be formed ${ }^{(32,37,38)}$. These reactive species have important biological functions, such as gene activation and participation in defence mechanisms; nevertheless, when overproduced, they may favour the oxidation of lipids, proteins and nucleic acids, resulting in oxidative stress, cell damage and loss of biological function ${ }^{(39)}$, increasing the risk of chronic diseases ${ }^{(40,41)}$. MDA is the most used biomarker of lipid peroxidation, and its levels have been positively related to cancer and $\mathrm{CVD}^{(40,42,43)}$.

The amount of HCA intake is variable worldwide. HCA intake was lower in the EPIC (European Prospective Investigation into Cancer and Nutrition) study ${ }^{(16)}(69 \mathrm{ng} / \mathrm{d})$ and in Sweden $^{(44)}(160 \mathrm{ng} / \mathrm{d})$ than in Brazil. In the USA, more than 25000 people consumed a mean of $455 \mathrm{ng} / \mathrm{d}^{(45)}$, similar to that found in the present study.

Brazilians, in particular, are widely exposed to these compounds because overcooked meat is a very popular food item ${ }^{(46)}$. In Sao Paulo, meat intake is excessive; more than $70 \%$ of people consume above the national and international meat recommendations ${ }^{(46,47)}$. However, meat intake was not significantly associated with oxidative stress in the present study.

We reported that participants who consumed grilled beef very well done had a higher MDA concentration than other participants, evidencing that intake of very well done grilled beef may have contributed to increase oxidative stress when compared with other doneness levels. This suggests that intake of beef prepared as above could increase the exposure to a potentially harmful component of diet, supporting previous findings relating the intake of red meat cooked at high temperature to colon cancer ${ }^{(48,49)}$.
An important consideration is that there are many sources of oxidative stress, such as smoking, radiation exposure, medication use, mitochondrial respiratory chain function, food intake and physical activity, in addition to HCA intake. For this reason, we adjusted regression models for other variables that could also contribute to increased oxidative stress.

HCA and PhIP intakes were reported to induce damage to other biological molecules, such as nucleic acids and proteins, leading to genetic damage and abnormal cell proliferation that may result in cancer ${ }^{(34,50,51)}$. Further studies exploring HCA intake and other early damage biomarkers, such as DNA adducts, are needed.

The present study showed that high intake of HCA and PhIP may contribute to increase oxidative stress independently of lifestyle factors, increasing the risk of chronic diseases, such as cancer and CVD.

\section{Acknowledgements}

The authors thank the São Paulo Research Foundation (FAPESP - procedural 2009/15831-0, 2012/10965-0) and the National Council of Technological and Scientific Development (CNPq procedural 481176/2008-0) for their financial support.

The scholarships were offered by São Paulo Research Foundation (FAPESP - procedural 2011/16225-6; 2012/10965-0; 2014/04607-0).

The authors declare that there is no conflict of interest.

The authors' contributions are as follows: A. M. C. carried out the study, biochemical analysis, data analyses, and drafted and wrote the manuscript; A. M. M. participated in the data analyses and drafted and wrote the manuscript; F. A. S. participated in the biochemical analysis and wrote the manuscript; A. P. M. L. participated in the biochemical analysis and drafted the manuscript; R. M. F. conceived the study, and participated in its design, coordination and drafted the manuscript; D. M. M. conceived the study, and participated in its design, coordination and helped to draft the manuscript.

\section{References}

1. Pereira PM \& Vicente AF (2013) Meat nutritional composition and nutritive role in the human diet. Meat Sci $\mathbf{9 3}, 586-592$. 
2. Daniel CR, Cross AJ, Koebnick C, et al. (2011) Trends in meat consumption in the USA. Public Health Nutr 14, 575-583.

3. Micha R, Wallace SK \& Mozaffarian D (2010) Red and processed meat consumption and risk of incident coronary heart disease, stroke, and diabetes mellitus: a systematic review and meta-analysis. Circulation 121, 2271-2283.

4. World Cancer Research Fund/American Institute for Cancer Research (2007) Food, Nutrition, Physical Activity, and the Prevention of Cancer: A Global Perspective. Washington, DC: AICR.

5. Aune D, Chan DS, Vieira AR, et al. (2013) Red and processed meat intake and risk of colorectal adenomas: a systematic review and meta-analysis of epidemiological studies. Cancer Causes Control 24, 611-627.

6. Zhu H, Yang X, Zhang C, et al. (2013) Red and processed meat intake is associated with higher gastric cancer risk: a meta-analysis of epidemiological observational studies. PLOS ONE 8, e70955.

7. Choi Y, Song S, Song Y, et al. (2013) Consumption of red and processed meat and esophageal cancer risk: meta-analysis. World J Gastroenterol 19, 1020-1029.

8. Salehi M, Moradi-Lakeh M, Salehi MH, et al. (2013) Meat, fish, and esophageal cancer risk: a systematic review and dose-response meta-analysis. Nutr Rev 71, 257-267.

9. Yang WS, Wong MY, Vogtmann E, et al. (2012) Meat consumption and risk of lung cancer: evidence from observational studies. Ann Oncol 23, 3163-3170.

10. Jägerstad M \& Skog K (2005) Genotoxicity of heat-processed foods. Mutat Res 1, 156-172.

11. Santarelli RL, Pierre F \& Corpet DE (2008) Processed meat and colorectal cancer: a review of epidemiologic and experimental evidence. Nutr Cancer 60, 131-144.

12. Ferguson LR (2010) Meat and cancer. Meat Sci 84, 308-313.

13. Hu J, La Vecchia C, Morrison H, et al. (2011) Salt, processed meat and the risk of cancer. Eur J Cancer Prev 20, 132-139.

14. Knize MG, Dolbeare FA, Carroll KL, et al. (1994) Effect of cooking time and temperature on the heterocyclic amine content of fried beef patties. Food Chem Toxicol 32, 595-603.

15. Skog K, Steineck G, Augustsson K, et al. (1995) Effect of cooking temperature on the formation of heterocyclic amines in fried meat products and pan residues. Carcinogenesis 16, 861-867.

16. Rohrmann S, Zoller D, Hermann S, et al. (2007) Intake of heterocyclic aromatic amines from meat in the European Prospective Investigation into Cancer and Nutrition (EPIC)Heidelberg cohort. Br J Nutr 98, 1112-1115.

17. Gunter MJ, Probst-Hensch NM, Cortessis VK, et al. (2005) Meat intake, cooking-related mutagens and risk of colorectal adenoma in a sigmoidoscopy-based case-control study. Carcinogenesis 26, 637-642.

18. Alaejos MS, Gonzalez V \& Afonso AM (2008) Exposure to heterocyclic aromatic amines from the consumption of cooked red meat and its effect on human cancer risk: a review. Food Addit Contam Part A Chem Anal Control Expo Risk Assess 25, 2-24.

19. Ollberding NJ, Wilkens LR, Henderson BE, et al. (2012) Meat consumption, heterocyclic amines and colorectal cancer risk the Multiethnic Cohort Study. Int $J$ Cancer 131, E1125-E1133

20. Thompson FE \& Byers T (1994) Dietary assessment resource manual. J Nutr 124, 2245S-2317S

21. Dwyer J, Picciano MF \& Raiten DJ (2003) Future directions for the integrated CSFII-NHANES: what we eat in America - NHANES. J Nutr 133, 576S-581S

22. Raper N, Perloff B, Ingwersen L, et al. (2004) An overview of USDA's dietary intake data system. I Food Compos Analysis 17, 545-555.
23. Pinheiro ABV, Lacerda EMA, Benzecry EH, et al. (2000) Tabela para Avaliação de Consumo Alimentar em Medidas Caseiras (Table for Household Measurements in Dietary Intake Assessment). São Paulo: Ed. Atheneu.

24. Fisberg RM \& Villar BS (2002) Manual de receitas e Medidas caseiras para Cálculo de Inquéritos Alimentares: manual elaborado para auxiliar o processamento de inquéritos alimentares (Manual of Recipes and Household Measurements for Food Surveys: Manual to Assist the Processing of Dietary Intake Surveys). São Paulo: Signus.

25. NDSR (2005) Nutrition Data System for Research. Version 2005. Minneapolis: University of de Minnesota.

26. Cantwell M, Mittl B, Curtin J, et al. (2004) Relative validity of a food frequency questionnaire with a meat-cooking and heterocyclic amine module. Cancer Epidemiol Biomarkers Prev 13, 293-298.

27. Bastos AS, Loureiro APM, Oliveira TF, et al. (2012) Quantitation of malonaldehyde in gingival crevicular fluid by a high-performance liquid-chromatography-based method. Anal Biochem 423, 141-146.

28. Hong YL, Yeh SL, Chang CY, et al. (2000) Total plasma malondialdehyde levels in 16 Taiwanese college students determined by various thiobarbituric acid tests and an improved high-performance liquid chromatography-based method. Clin Biochem 33, 619-625.

29. World Health Organization (2000) Obesity: Preventing and Managing the Global Epidemic. Report of a World Health Organization Consultation. WHO Obesity Technical Report Series no. 284. Geneva: WHO

30. Lipschitz DA (1994) Screening for nutritional status in the elderly. Prim Care 21, 55-67.

31. Maeda H, Sato K, Akaike T (1995) Superoxide radical generation from heterocyclic amines. Princess Takamatsu Symp 23, 103-112.

32. Maeda H, Sawa T, Yubisui T, et al. (1999) Free radical generation from heterocyclic amines by cytochrome $\mathrm{b} 5$ reductase in the presence of NADH. Cancer Lett 143, 117-121.

33. Li R, Li W, Xie J, et al. (2012) Lipid peroxidation in different tissues of rats treated with 2-amino-1-methyl-6-phenylimidazo $[4,5-b]$ pyridine. Wei Sheng Yan Jiu 41, 102-105.

34. Li R, Tian J, Li W, et al. (2013) Effects of 2-amino-1-methyl6-phenylimidazo $[4,5-b]$ pyridine (PhIP) on histopathology, oxidative stress, and expression of c-fos, c-jun and p16 in rat stomachs. Food Chem Toxicol 55, 182-191.

35. Stocker R \& Keaney JF Jr. (2004) Role of oxidative modifications in atherosclerosis. Physiol Rev 84, 1381-1478.

36. Dalle-Donne I, Rossi R, Colombo R, et al. (2006) Biomarkers of oxidative damage in human disease. Clin Chem 52, 601-623.

37. Felton JS \& Malfatti MA (2006) What do diet-induced changes in phase I and II enzymes tell us about prevention from exposure to heterocyclic amines? J Nutr 136, 2683S-2684S

38. Turesky RJ \& Le Marchand L (2011) Metabolism and biomarkers of heterocyclic aromatic amines in molecular epidemiology studies: lessons learned from aromatic amines. Chem Res Toxicol 24, 1169-1214.

39. Barbosa KBF, Costa NMB, Alfenas RCG, et al. (2010) Oxidative stress: concept, implications and modulating factors. Rev Nutr 23, 629-643.

40. Kryston TB, Georgiev AB, Pissis P, et al. (2011) Role of oxidative stress and DNA damage in human carcinogenesis. Mutat Res 711, 193-201.

41. Vassalle C, Bianchi S, Bianchi F, et al. (2012) Oxidative stress as a predictor of cardiovascular events in coronary artery disease patients. Clin Chem Lab Med 50, 1463-1468. 
42. Vasconcelos SML, Goulart MOF, Moura JBF, et al. (2007) Espécies reativas de oxigênio e de nitrogênio, antioxidantes e marcadores de dano oxidativo em sangue humano: principais métodos analíticos para sua determinação (Reactive species of oxygen and nitrogen, antioxidants and oxidative damage markers in human blood: main analytical methods for its determination). Química Nova 30, 1323-1338.

43. Perse M (2013) Oxidative stress in the pathogenesis of colorectal cancer: cause or consequence? Biomed Res Int 2013, 725710 .

44. Augustsson K, Skog K, Jagerstad M, et al. (1997) Assessment of the human exposure to heterocyclic amines. Carcinogenesis 18, 1931-1935.

45. Bogen KT \& Keating GA (2001) US dietary exposures to heterocyclic amines. J Expo Anal Environ Epidemiol 11, $155-168$

46. de Carvalho AM, César CL, Fisberg RM, et al. (2013) Excessive meat consumption in Brazil: diet quality and environmental impacts. Public Health Nutr 16, 1893-1899.
47. Carvalho AM, Cesar CLG, Fisberg RM, et al. (2014) Meat consumption in Sao Paulo - Brazil: trend in the last decade. PLOS ONE 9, e96667.

48. World Cancer Research Fund/American Institute for Cancer Research (2010) Systematic Literature Review Continuous Update Project Report: The Associations between Food, Nutrition and Physical Activity and the Risk of Colorectal Cancer. Washington, DC: AICR.

49. Sinha R, Peters U, Cross AJ, et al. (2005) Meat, meat cooking methods and preservation, and risk for colorectal adenoma. Cancer Res 65, 8034-8041.

50. Schraufstätter I, Hyslop PA, Jackson JH, et al. (1988) Oxidantinduced DNA damage of target cells. J Clin Invest $\mathbf{8 2}$, 1040-1050.

51. Lin DX, Kaderlik KR, Turesky RJ, et al. (1992) Identification of $N$-(deoxy-guanosine-8-yl)-2-amino-1-methyl-6-phenylimidazo- $[4,5-b]$ pyridine as the major adduct formed by the food-borne carcinogen, 2-amino-1-methyl-6-phenylimidazo [4,5-b] pyridine, with DNA. Chem Res Toxicol 5, 691-697. 